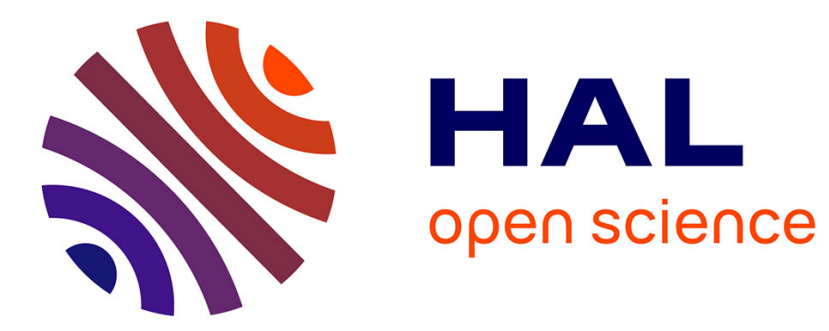

\title{
EBIC investigations of thick SOI layers
}

\author{
M. Kittler, B. Tillack, W. Hoppe, W. Seifert, R. Banisch, H.H. Richter, A. \\ Rocher
}

\section{To cite this version:}

M. Kittler, B. Tillack, W. Hoppe, W. Seifert, R. Banisch, et al.. EBIC investigations of thick SOI layers. Revue de Physique Appliquée, 1988, 23 (3), pp.281-288. 10.1051/rphysap:01988002303028100 . jpa-00245772

\section{HAL Id: jpa-00245772 https://hal.science/jpa-00245772}

Submitted on 1 Jan 1988

HAL is a multi-disciplinary open access archive for the deposit and dissemination of scientific research documents, whether they are published or not. The documents may come from teaching and research institutions in France or abroad, or from public or private research centers.
L'archive ouverte pluridisciplinaire HAL, est destinée au dépôt et à la diffusion de documents scientifiques de niveau recherche, publiés ou non, émanant des établissements d'enseignement et de recherche français ou étrangers, des laboratoires publics ou privés. 
Classification

Physics Abstracts

$61.70-73.60$

\title{
EBIC investigations of thick SOI layers
}

\author{
M. Kittler, B. Tillack, W. Hoppe, W. Seifert, R. Banisch, H. H. Richter and A. Rocher ( $\left.{ }^{1}\right)$ \\ Institut für Halbleiterphysik der AdW, W.-Korsing-Str. 2, DDR-1200 Frankfurt (Oder), G.D.R. \\ (1) Laboratoire d'Optique Électronique du CNRS, 29, Rue J. Marvig, F-31055 Toulouse, France
}

(Reçu le 21 juillet 1987, révisé le 15 décembre 1987, accepté le 16 décembre 1987)

\begin{abstract}
Résumé. - Le comportement électrique de couches épaisses de silicium déposées sur isolant (SOI) est étudié par SEM/EBIC. Ces couches, de plusieurs microns d'épaisseur, sont recristallisées par déplacement d'une zone fondue faisant intervenir ou non un germe. Des contrastes EBIC particuliers sont interprétés comme des hétérogénéités de dopant dont l'origine est reliée aux modes de croissance réalisés à partir de germe orienté.
\end{abstract}

\begin{abstract}
Thick SOI layers obtained by zone melting with and without seeds, respectively, have been investigated by EBIC with respect to their electrical properties (electrical homogeneity, electrically active defects, minority-carrier diffusion length). A variety of inhomogeneities being partly of complex origin has been observed. Their formation is affected by existence of seeds. Besides usual dark contrasts due to defects acting as recombination site there is evidence that some contrast phenomena are caused by dopant inhomogeneities.
\end{abstract}

\section{Introduction.}

The production of monocrystalline silicon layers on insulators (SOI) has been the subject of numerous investigations in the recent years [1]. A SOI technology has various attractive possibilities of application in microelectronics and offers completely new technological solutions [2]. So it could provide an advantageous isolation technique for submicrometer VLSI preventing coupling and increasing circuit speed. Other possible applications are radiationhardened devices, high-voltage devices and threedimensional integrated circuits. Besides investigations aimed at producing monocrystalline films by different methods [3] the estimation of their crystallographic and electrical properties is of special interest. While there are detailed investigations about thin SOI films $(0.5 \mu \mathrm{m})$ only few information exists concerning preparation and properties of thicker layers (up to several ten $\mu \mathrm{m}$ ).

The aim of the present study is to receive information about the electrical characteristics of thick SOI layers, especially on their homogeneity and content of electrically active defects which may be considered as a qualitative measure for the applicability of SOI wafers in electronic device manufacturing.

The SOI layers were obtained by zone-melting recrystallization of polycrystalline silicon using a halogen-lamp strip heater [4-6]. The samples to be recrystallized were prepared in the following way: (100) silicon was thermally oxidized up to a thickness of $1 \mu \mathrm{m}$. Then polycrystalline silicon having thicknesses up to $25 \mu \mathrm{m}$ was deposited. Finally, the samples were covered with a cap (CVD $\mathrm{SiO}_{2}$ and CVD $\mathrm{Si}_{3} \mathrm{~N}_{4}$ ) which was removed again after recrystallization. In some wafers the thermal oxide had been patterned before depositing polycrystalline silicon in order to produce an array of seeding windows. So, SOI wafers recrystallized with and without seeds were produced and had to be characterized with respect to their electrical homogeneity.

The EBIC mode of the scanning electron microscope is a well suited diagnostic tool for this purpose as it allows to investigate both recombination proper- 


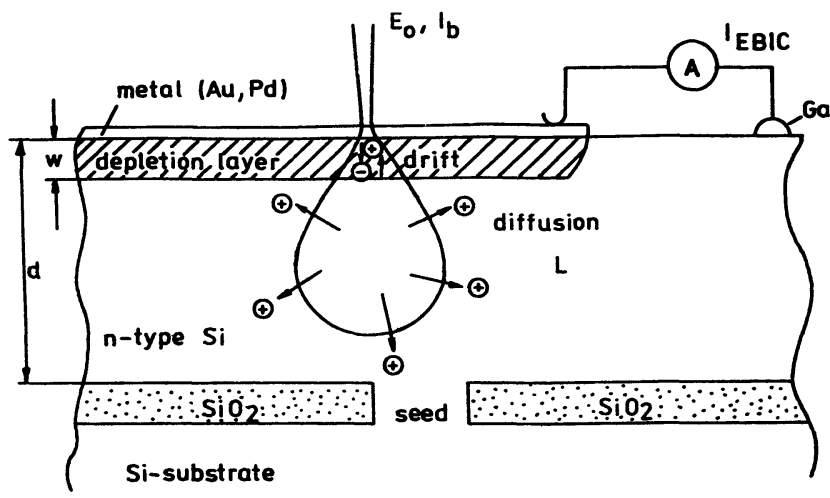

Fig. 1. - Sample structure and experimental set-up for EBIC investigations.

ties and doping and to image electrical inhomogeneities (e.g. electrically active defects) with spatial resolution in the $\mu \mathrm{m}$ range. Figure 1 shows a sketch of the experimental set-up used. Evaporated Schottky contacts (Au or $\mathrm{Pd}$ for $\mathrm{n}-\mathrm{Si}, \mathrm{Al}$ for $\mathrm{p}-\mathrm{Si}$ ) were used for charge collection. For detailed description of EBIC the reader is referred to [7].

In this paper emphasis is put on SOI wafers obtained by seeding recrystallization because our results on defect structure and electrical parameters favour seeding recrystallization as a method resulting in better electrical properties [5, 6].

\section{EBIC observations on SOI layers.}

During recrystallization of the polycrystalline silicon layer extended crystal defects originate. Large areas which contain subboundaries and are separated from each other by grain boundaries of larger angles are typical of recrystallization without seeds. In the case of seeding recrystallization only subboundaries and dislocation arrays are observed. In the following no distinction will be made between the different types of grain boundaries and the general term grain boundary (GB) will be used throughout the paper.

Extended crystal defects like GB's and dislocations usually lead to a reduction of the EBIC signal because they represent regions of enhanced carrier recombination. Consequently, they appear as dark contrasts. It is widely accepted that this recombination contrast is the result of interactions between extended crystal defects and impurities, see e.g. [8].

2.1 SOI LAYERS RECRYSTALLIZED WITHOUT SEEDS. - The layer investigated here was phosphorus-doped $(\rho \simeq 5 \mathrm{ohm} \mathrm{cm})$ and about $8 \mu \mathrm{m}$ thick. Figure 2 shows two EBIC micrographs of the layer taken at a beam energy $E_{0}=23 \mathrm{keV}$ and beam currents $I_{\mathrm{b}}$ around $100 \mathrm{pA}$ (Fig. 2a) and around $1 \mathrm{nA}$ (Fig. 2b). These beam-current conditions are referred to as low injection and high injection, respectively. The low injection micrograph reveals dark line-shaped contrasts which are nearly parallel to the scan direction of the strip heater. These contrasts (e.g. A and B) are caused by GB's and demonstrate enhanced recombination. Weak diffuse contrasts (labelled $\beta$ ) are visible besides the GB's, similar to p-type EFG silicon [9]. Note that the defect-free regions 1 and 2 are characterized by about the same grey level, i.e. the same EBIC signal. Several differences are easily seen between low and high injection level, as demonstrated in figure $2 a$ and figure $2 b$ :

i) A marked signal difference appears between the defect-free regions 1 and 2 under high injection.

ii) The contrast of GB B remains qualitatively unchanged while a additional bright halo appears around GB A. The contrast width at $E_{0}=23 \mathrm{keV}$ and low injection is about $10 \mu \mathrm{m}$. At high injection the dark contrast region is reduced and bright haloes on both sides of the GB appear. Similar bright haloes were observed by other authors $[10,11]$, too.

iii) Noteworthy are also the weak light stripes (S) in figure 2 marked by arrows. Figure 3 shows this feature in more detail compairing images obtained at high beam energy/low injection and low beam energy/high injection. According to the arguments given in the Appendix the light stripes in figure 3a and dark stripes in figure $3 \mathrm{~b}$, respectively, are recognized as regions of reduced doping. The doping inhomogeneities are perpendicular to the scan direction of the strip heater and are supposed to be caused by discontinuous movement of the strip heater. Some interaction with the two GB's is also seen.

Apart from these doping inhomogeneities one can up to now only speculate about the causes of the effects observed, although injection effects on recombination properties are reported in various papers [12-15]. Among the causes which possibly could contribute to the injection effects are : different properties and densities of centres involved in recombination in the layer volume, injection dependent electrical barriers [16], recombination at the layer/oxide interface, influence of grain orientation... The unusual contrast behaviour at GB A may be, generally speaking, understood as a result of gettering of point defects [11].

\subsection{SOI LAYERS OBTAINED BY SEEDING RECRYS-} TALLIZATION. - The aim of using a crystallization seed is to prevent GB formation in the area near the seed. Therefore seeding windows were arranged as a frame surrounding the SOI area. The frame-like form of the seed was chosen to allow investigations of the influence of seeding geometry on the arrangement of defects. In this way conclusions could be drawn concerning the action of thermal gradients at the crystallization front $[5,6]$. For the studies shown 

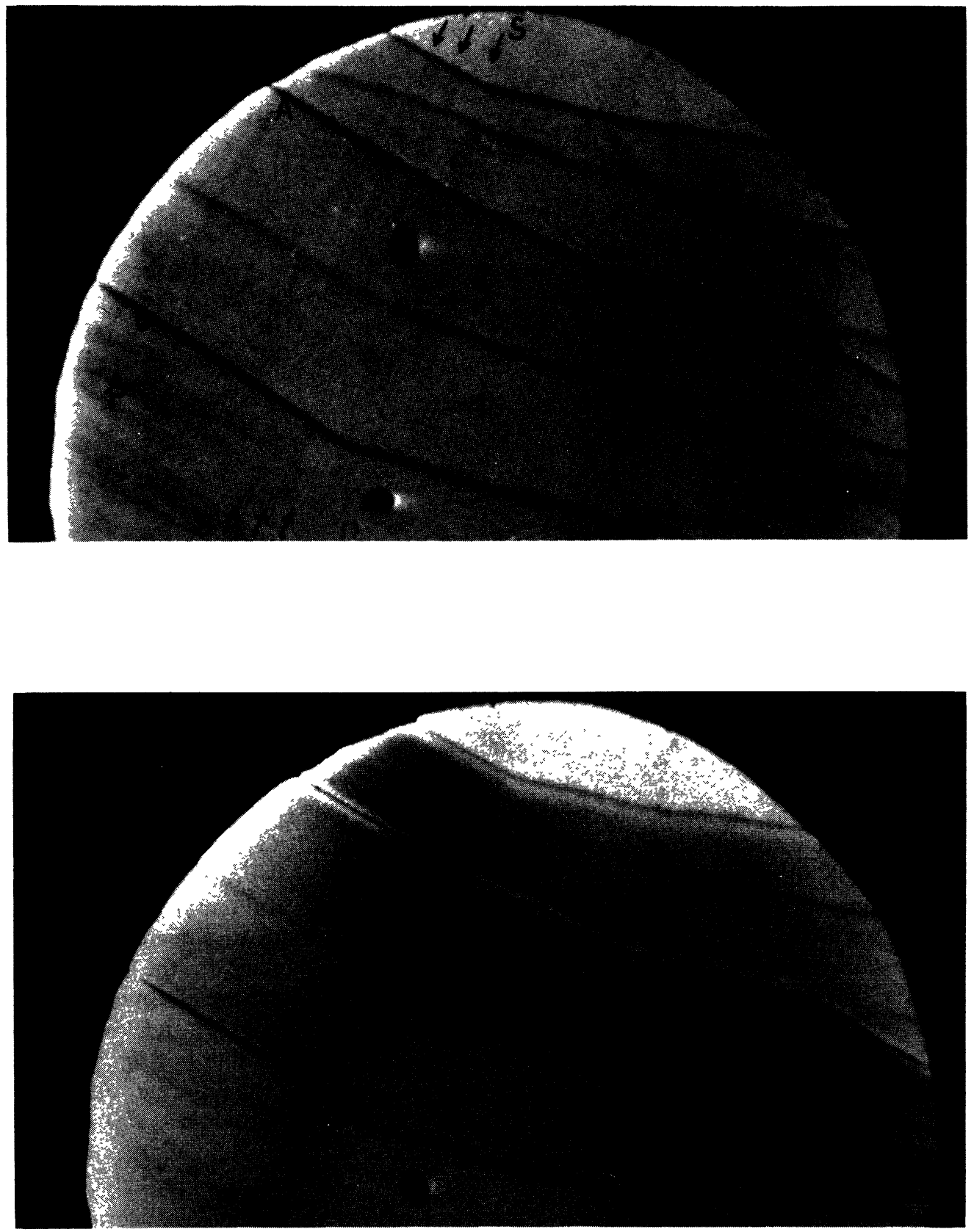

b)

Fig. 2. - EBIC micrograph of an SOI layer recrystallized without seed, overview : a) $E_{0}=23 \mathrm{keV}$, low injection, b) $E_{0}=23 \mathrm{keV}$, high injection. Note the weak doping stripes marked by arrows and label $\mathrm{S}$.
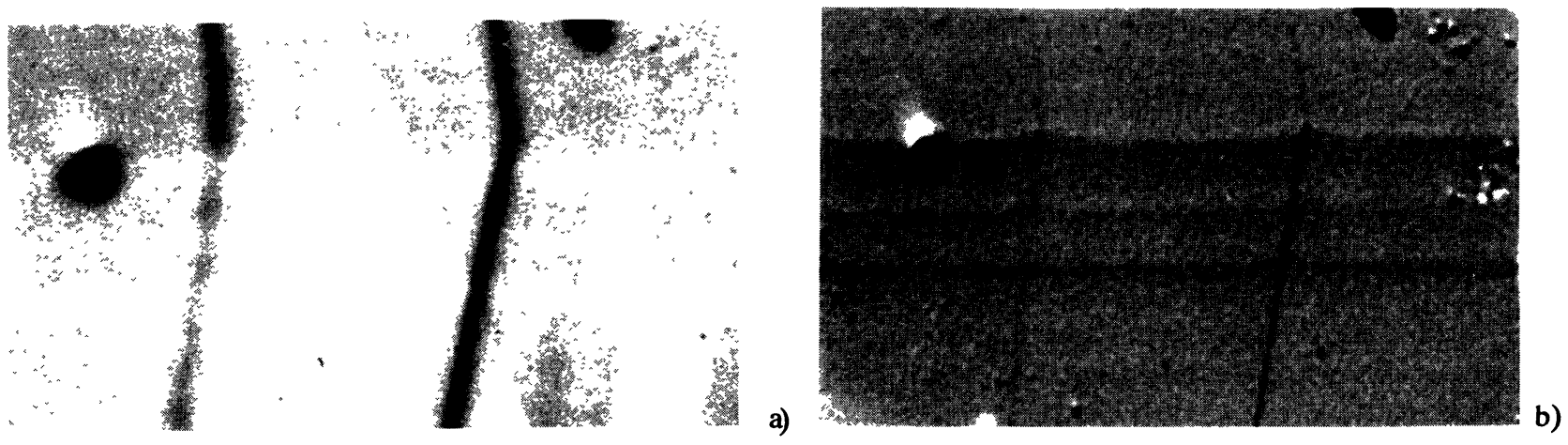

Fig. 3. - Doping stripes in the SOI layer shown in figure 2. a) $E_{0}=34 \mathrm{keV}$, low injection, b) $E_{0}=9 \mathrm{keV}$, high injection. 


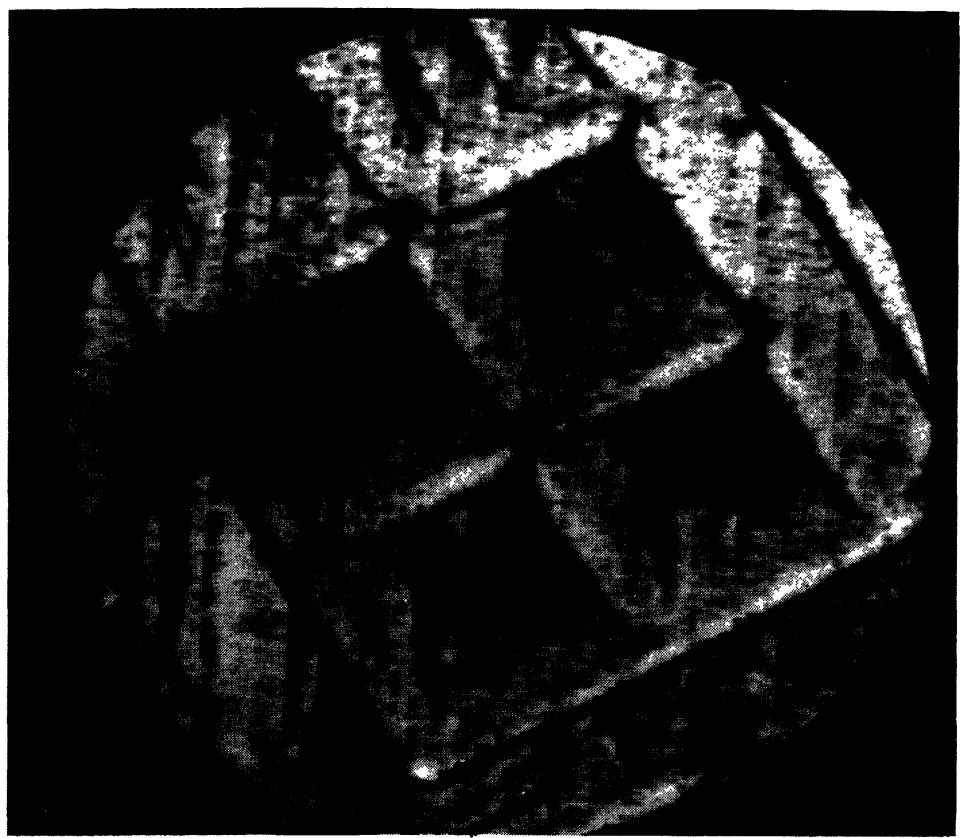

Fig. 4. - EBIC $\left(E_{0}=30 \mathrm{keV}\right)$ micrograph of the SOI layer obtained by seeding recrystallization - overview. The dark spot on the left is the contact to the Schottky barrier. Note the bright regions (b.r.) near the dark contrast patterns forming right angles.

here the recrystallization was carried out by moving the molten zone parallel to the diagonal of the seeding frame in $\langle 100\rangle$ direction.

The layers investigated were phosphorus-doped. Before preparing Au Schottky contacts for EBIC investigations the sample was lapped and polished for smoothing the surface. The remaining layer thickness was about $d=13 \mu \mathrm{m}$. Figure 4 shows a low-magnification EBIC micrograph of the SOI layer with contrast pattern completely different from layers recrystallized without seed. The striking feature is a dark contrast pattern forming nearly right angles and being directly related to the seeds. Near these contrast patterns a slight increase of the collected EBIC signal (bright regions) is found. The area at the right corner of figure 4 is shown in figure 5 at higher magnification.

Figure $5 \mathrm{a}$ is an EBIC micrograph recorded at $E_{0}=40 \mathrm{keV}$ and low injection. The seed is imaged as bright frame. This is thought to be due to efficient recombination at the layer/oxide interface. So, the EBIC current collected above the oxide is lower than the current collected above the seed. Further there is an area free of defects behind the starting seed whereas GB's are found in the SOI region near the following seed. At $E_{0}=30 \mathrm{keV}$ and low injection (Fig. 5b) the bright contrast caused by the seeds disappears while the GB contrasts remain and get somewhat clearer. Moreover, a region of slightly enhanced signal is observed above and right to the two long perpendicular GB's (compare also Fig. 4 where this feature is more pronounced).
A different contrast behaviour is observed at $E_{0}=5 \mathrm{keV}$ and high injection (Fig. 5c). The outer GB's appear bright now and a dark region is observed between them and the seed. Lowering the beam current leads to a decrease of these contrasts. The GB's extending to the centre are visible in usual, but low contrast. At medium beam energies $\left(10 \mathrm{keV}<E_{0}<30 \mathrm{keV}\right)$ and low injection the contrasts are similar to those of figure $5 \mathrm{~b}$. The situation becomes, however, different at higher injection. Dark regions between the outer GB's and contrast reduction at GB's in the centre of the recrystallized area are then found. This injection-dependent behaviour of the GB contrast is in accordance with results of systematic EBIC investigations carried out at GB's in bicrystals [15]. An example of such injection-level dependence is given in figure 6. On the contrary, the dramatic contrast change as at the outer GB's (Figs. 5b and 5c) was observed for the first time and may be interpreted as caused by variations of the Schottky-barrier depletion-layer width, i.e. by inhomogeneities of the dopant concentration (compare Apendix). The same mechanism seems to be responsible for the light (Figs. 4 and 5b) and dark (Fig. 5c), respectively, regions between outer GB's and seeds. Figure 5d sketches all the results obtained for the SOI layer with seeds :

i) The GB's B exhibit usual contrast behaviour and are therefore thought to be regions characterized by enhanced recombination activity, essentially.

ii) The near surrounding of GB's $A$ is charac- 

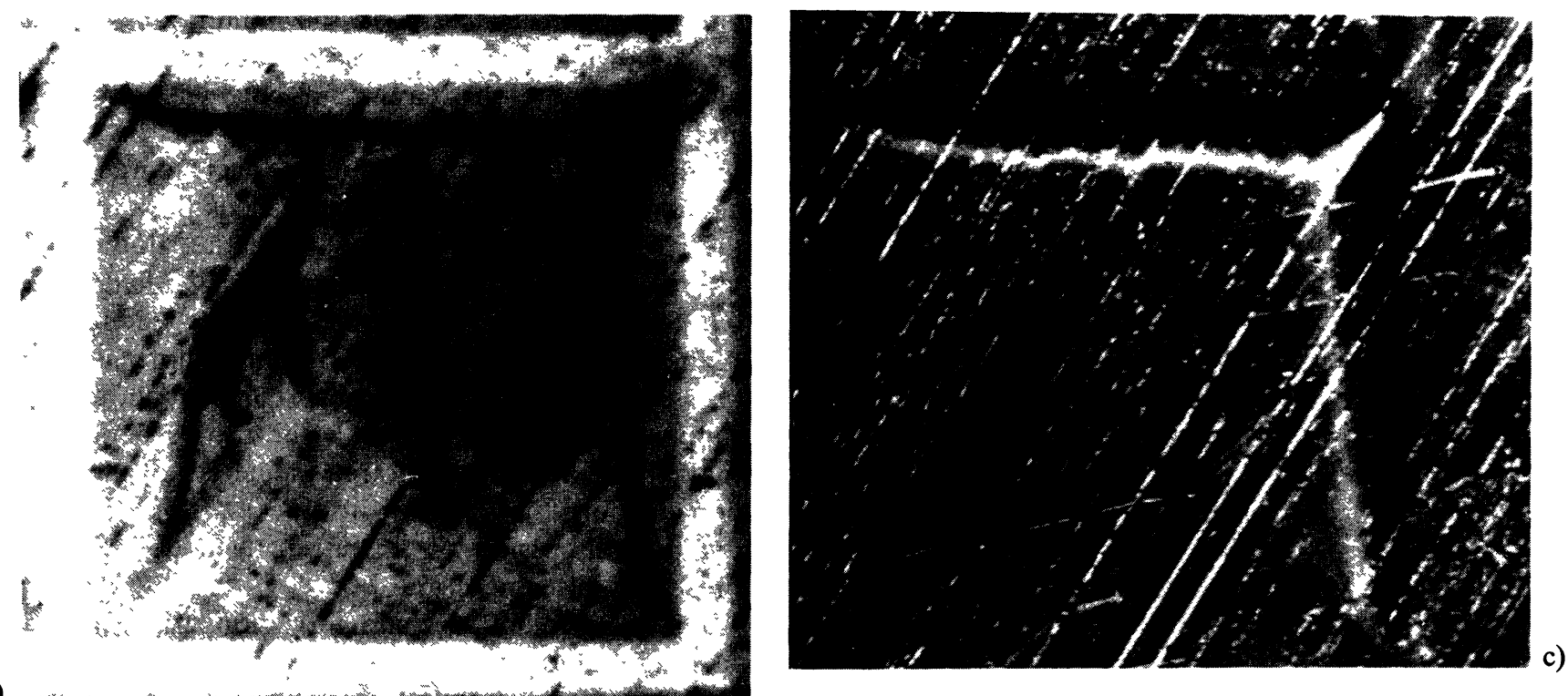

a)

b)
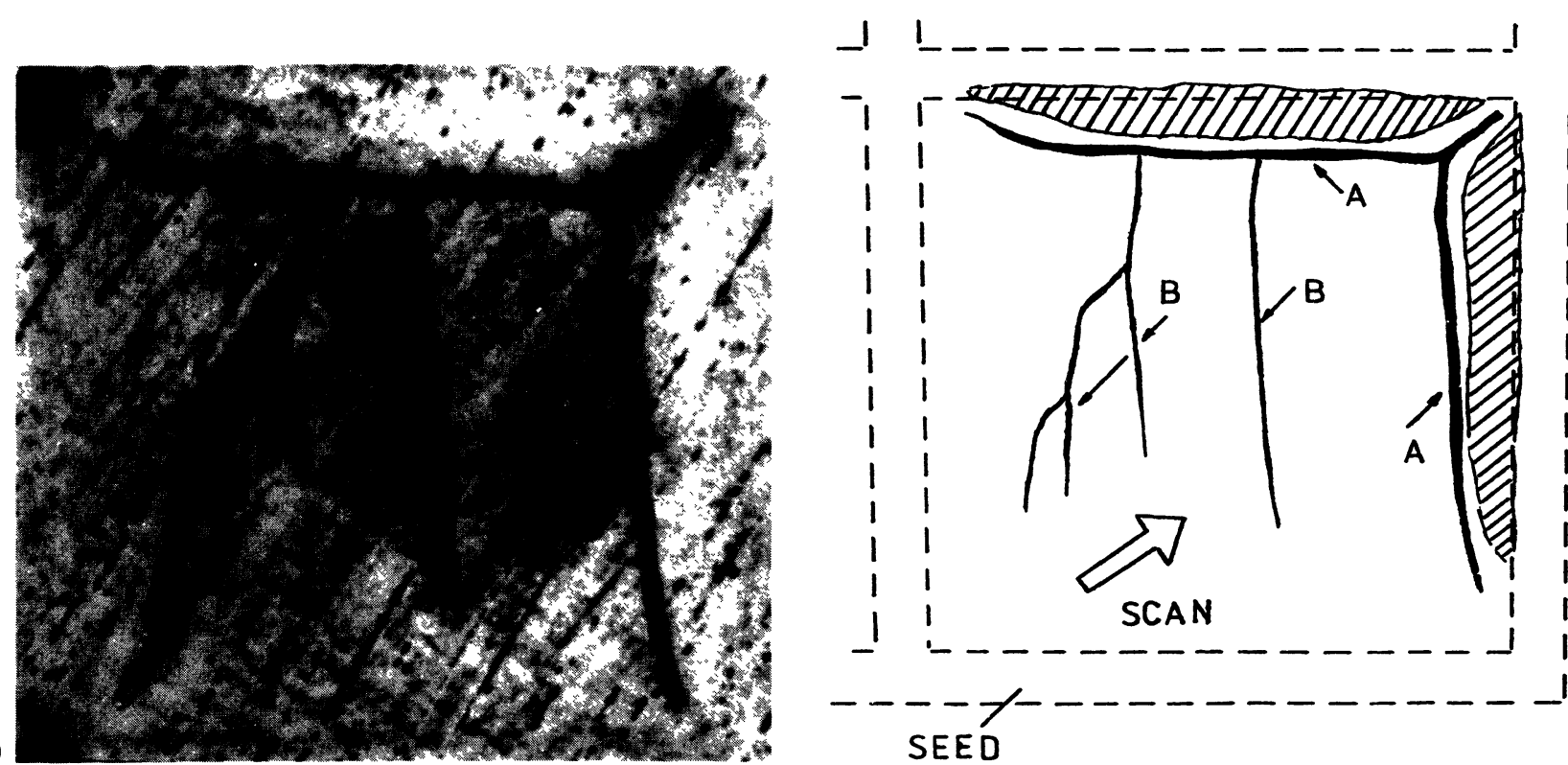

Fig. 5. - EBIC micrographs of an SOI island. a) $E_{0}=40 \mathrm{keV}$, low injection. b) $E_{0}=30 \mathrm{keV}$, low injection. c) $E_{0}=5 \mathrm{keV}$, high injection. d) Sketch of the recrystallized SOI island. The line-shaped contrasts passing the micrographs nearly diagonally are due to surface scratches.

terized by both enhanced dopant concentration and enhanced recombination activity.

iii) The shaded areas are regions of reduced dopant concentration.

So, we arrived at the hypothesis that the near surrounding of the outer GB's is enriched with dopants while the region between GB's and seed is depleted of dopant atoms.

\section{Measurements of minority-carrier diffusion length.}

The diffusion length $L$ is an important parameter characterizing the material perfection. It is related to recombination lifetime $\tau_{r}$ and minority-carrier dif- fusivity $D$ by $L^{2}=D \tau_{\mathrm{r}}$. The diffusion length in the SOI layers can be determined with relatively high spatial resolution from measurements of the energy dependence of the charge collection efficiency $[17,18]$. Such measurements were carried out on an n-type SOI layer of $25 \mu \mathrm{m}$ thickness obtained by seeding recrystallization of polycrystalline silicon. The following values were established by this technique : $L \simeq 15 \mu \mathrm{m}$ in the defect-free area above the seed and $L \simeq 8 \mu \mathrm{m}$ in the area above the oxide. The smaller diffusion length above the oxide is due to defects in the layer mainly. Nevertheless, both diffusion lengths are in the order of effective diffusion lengths found in monocrystalline $\mathrm{Cz}$ silicon wafers after intrinsic gettering [19]. From the point 


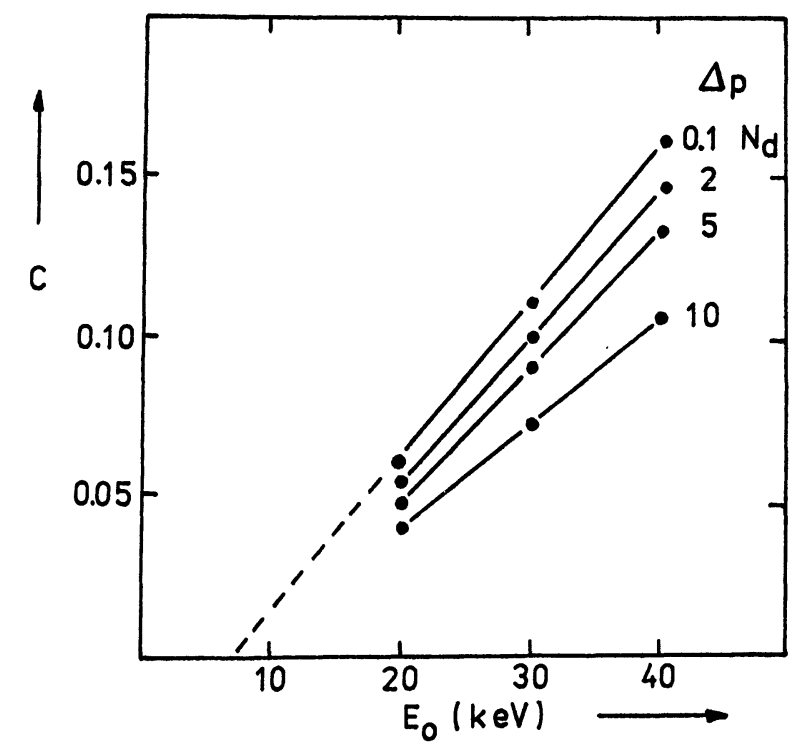

Fig. 6. - Dependence of GB EBIC-contrast $c$ on beam energy $E_{0}$. Parameter is the injection level $\Delta p$ expressed in units of dopant concentration $N_{\mathrm{d}}$ [15].

of view of average recombination properties the recrystallized layers are, therefore, thought to be acceptable for producing devices. One has to keep in mind, however, that devices are sensitive also to local microscopic inhomogeneities, so that a parameter averaged over a given area is not a sufficient characteristic of the material perfection.

\section{Discussion.}

EBIC investigations were shown to provide valuable information on electrical properties and homogeneity of thick SOI layers. The diffusion-length values measured in the defect-free regions of the SOI layers recrystallized with seeds are indicative of a quite high material perfection. On the other hand, a variety of inhomogeneities being partly of complex origin was observed in the layers, too. Besides the usual contrast causes (defect as recombination site) there is evidence that some contrast phenomena are caused by dopant inhomogeneities. Thereby, contrasts interpreted as being due to dopant inhomogeneities were found to appear both in conjunction with GB's as well as without direct connection to extended crystal defects.

Seeding recrystallization provides SOI layers which exhibit an area free of electrical active defects near the seed followed by an area with GB's. The observed dopant inhomogeneities are related to the process of seeding recrystallization and can be explained in the following way: during the zone melting recrystallization a solidification process starting at the seed occurs. The molten zone moves over the $\mathrm{SiO}_{2}$ region and reaches the following seed. The difference in heat conduction between $\mathrm{Si}$ and $\mathrm{SiO}_{2}$ causes a heat flow through the seeding windows into the Si substrate. When the molten zone passes the following seed a backward solidification takes place, i.e. a molten area remains between «normal » and backward solidification fronts. The backward solidification is a result of a local temperature decrease caused by the enlarged heat flow through the following seed window. At the liquid/solid interface the molten area is enriched with dopants due to segregation. Finally, defects arise (see feature $A$ in Fig. 5d) at the place where both « normal " and backward solidification fronts come together. A support of our explanation is the fact (see Fig. 5d) that the extent of the area depleted of dopants depends on the distance to the starting seed. A detailed discussion of the mechanism described is presented elsewhere $[5,6]$.

For more detailed characterization of the microscopic inhomogeneities combined EBIC/TEM investigations are in preparation.

\section{Appendix : EBIC detection of doping inhomogen- eities.}

In the SOI layers investigated a variety of electrical inhomogeneities have been found. Among them there are also contrasts having doping origin (for example see Fig. 3). For better understanding of the contrast mechanism the arguments for interpreting contrasts as being due to doping inhomogeneities shall be discussed now.

Figure 7 shows two EBIC micrographs of the same region of a phosphorus-doped $(\rho \simeq 50 \mathrm{ohm}$ $\mathrm{cm}$ ) FZ silicon sample which was known to contain doping striations. These striations are visible as EBIC contrasts in both the clear figure $7 a$ and the noisy figure $7 \mathrm{~b}$. The characteristic feature is the inversion of the striation EBIC contrast with changing $E_{0}$ which is thought to be an evidence of doping inhomogeneities [7]. The underlying mechanism is the following: for large $E_{0}$ and sufficiently low injection (Fig. 7b) the contrast observed results from the fact that the collection efficiency of carriers generated within the Schottky-contact space-charge region (SCR) of width $w$ is $\eta_{\mathrm{SCR}} \rightarrow 1$ whereas the portion of carriers generated in the neutral semiconductor beneath the SCR has a collection efficiency of $\eta_{\text {neutral }}<1$. This is because carriers in the neutral semiconductor regions are subject to recombination during their diffusion to the SCR edge. Consequently a wider depletion layer (lower doping) leads to higher collection, i.e. bright stripes correspond to regions of lower doping. At low beam energy (Fig. 7a) the whole generation volume characterized by the electron range $R$ lies in the depletion layer ( $R \simeq 1 \mu \mathrm{m}, w \simeq 2.5 \mu \mathrm{m})$. No contrast is observed at low injection because of $\eta_{\mathrm{SCR}} \rightarrow 1$. Clear striations appear, however, for increased beam currents as shown in the micrograph. This is due to a increasing 


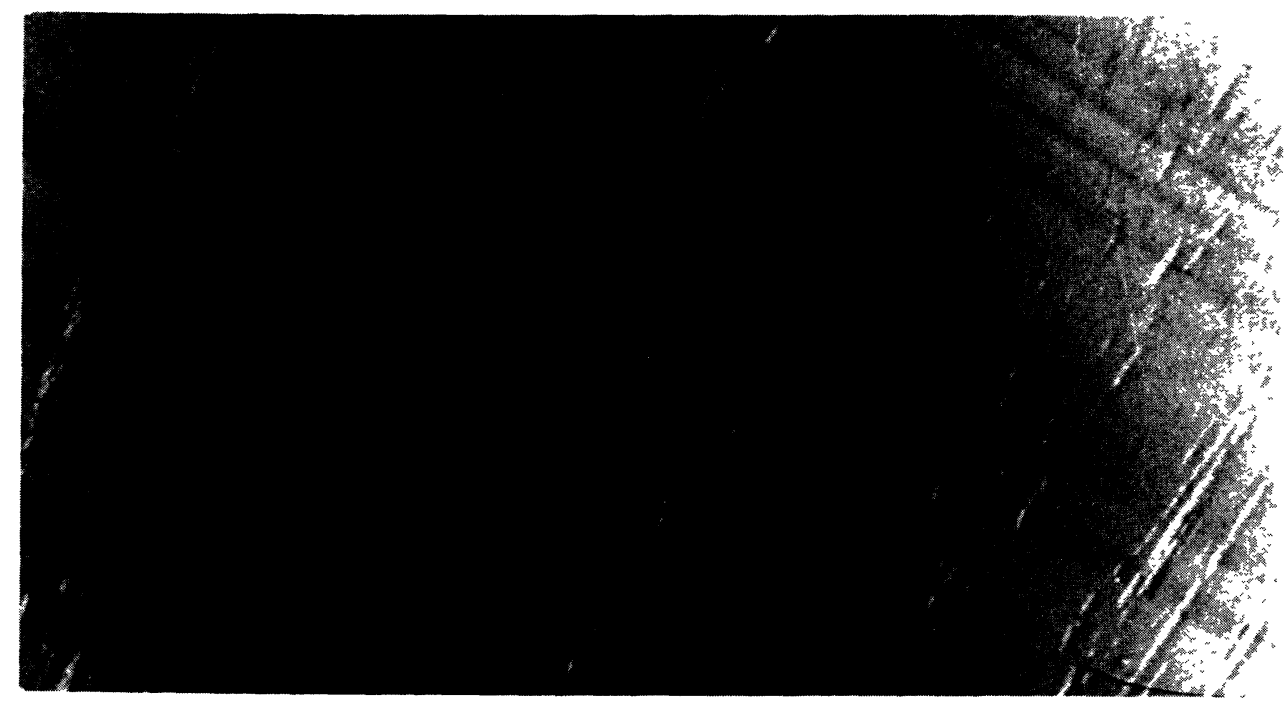

a)

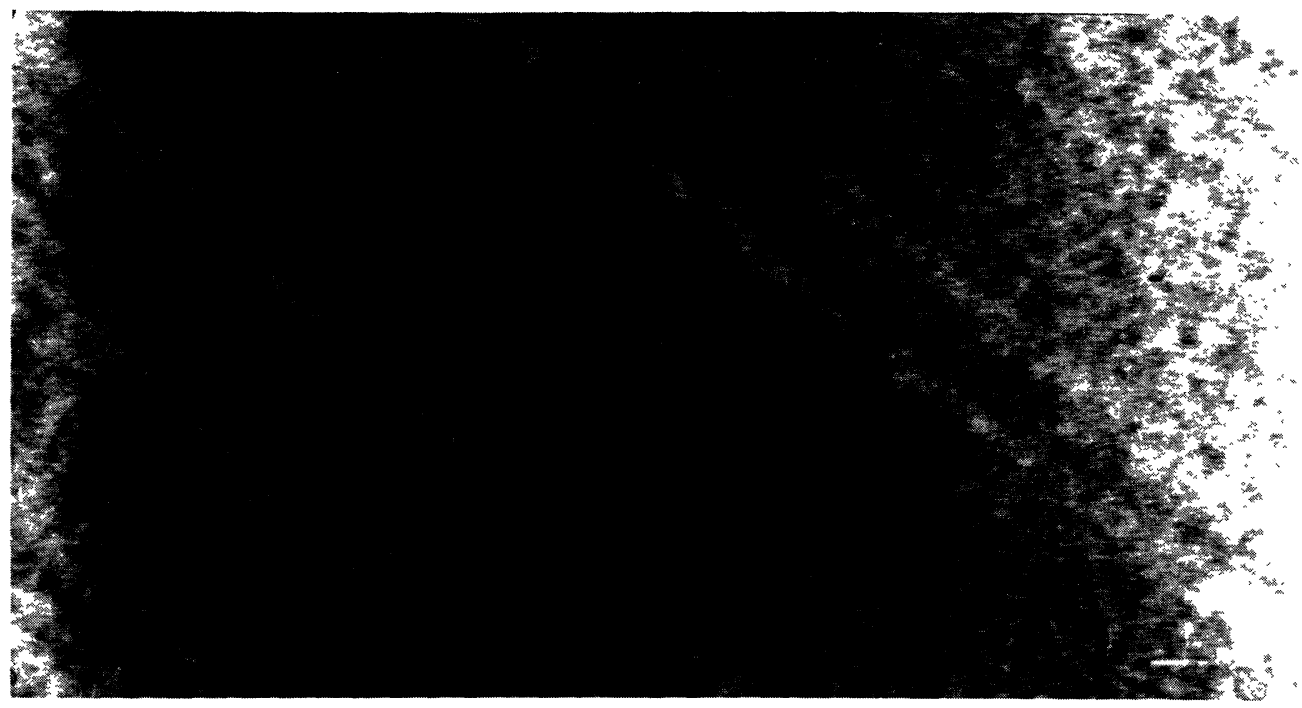

b)

Fig. 7. - Illustration of the method of detecting doping inhomogeneities : FZ silicon sample with doping striations. a) $E_{0}=10 \mathrm{keV}$, beam current $I_{\mathrm{b}} \simeq 300 \mathrm{pA}$. b) $E_{0}=39 \mathrm{keV}, I_{\mathrm{b}} \simeq 100 \mathrm{pA}$.

screening of the electrical field in the SCR by the beam-generated electron-hole plasma. So, the generated carriers are not immediately separated and recombination can occur in the SCR leading to $\eta_{\mathrm{SCR}}<1$. As there is a lower electrical field in regions of lower doping this effect is more pronounced in low-doped regions. Therefore regions of lower doping are imaged dark now. This contrast inversion is characteristic of contrast due to doping inhomogeneities. It should be emphasized here that the EBIC method of detecting doping inhomogeneities is very sensitive as was shown by comparison with spreading-resistance measurements, see also [7].

\section{References}

[1] Celler, G. K., CRC Critical Rev. in Solid State and Materials Science 12 (1985) 193.

[2] Tsaur, B. Y., MRS Symp. Proc. 35 (1985) 641.

[3] JASTRZEBSKI, L., J. Cryst.Growth 70 (1984) 253.

[4] Tillack, B., Mö́cK, P., Banisch, R., Reinboth, R., RICHTER, H. H., VOELSKOW, M., MATTHÄI, J. and Wieser, E., Phys. Status Solidi A 94 (1986) 871
[5] Tillack, B., Richter, H. H. and Banisch, R., published in EPM '87 Dresden, October 7-11 1987.

[6] Tillack, B., Banisch, R. and Richter, H. H., Proc. 2nd GADEST (1987), Garzau, Acad. Sci. GDR, Ed. H. Richter, p. 308-312.

[7] Leamy, H. J., J. Appl. Phys. 53 (1982) R51. 
[8] Battistella, F., Rocher, A. and George, A., MRS Symp. Proc. 59 (1986) 347.

[9] Ho, C. T., Sandstrom, P. B. and Dube, C. E., Solid-State Electron. 29 (1986) 495.

[10] Dianteill, C., Thesis, LOE-Toulouse (1983).

[11] STÜtZler, F. J., TAPFER, L. and QueisSer, H. J., Proc. 14th ICDS (1986), Paris, in Materials Science Forum, 10 (1986) 229.

[12] Davidson, S. M. and Dimitriadis, C. A., J. Microscopy 118 (1980) 275.

[13] Hanoka, J. I. and Bell, R. O., Ann. Rev. Mater. Sci. 11 (1981) 353.

[14] Davidson, S. M., InNes, R. M. and Lindsay, S. M., Solid-State Electron. 25 (1982) 261.
[15] Battistella, F. and Rocher, A., Semicond. Sci. Technol. 2 (1987) 226.

[16] Ziegler, E., Siegel, W., Blumtritt, H. and Breitenstein, O., Phys. Stat. Sol. A 72 (1982) 593.

[17] Wu, C. J. and Wittry, D. B., J. Appl. Phys. 49 (1978) 2827.

[18] Kittler, M. and Schröder, K.-W., Phys. Stat. Sol. A 77 (1983) 139.

[19] Kittler, M. and Seifert; W., Phys. Stat. Sol. A 99 (1987) 559. 